\title{
Estratégias de Educação em Saúde e a qualidade do cuidar e ensinar em Pediatria: a int eração, o vínculo e a confiança no discurso dos profissionais
}

\author{
Maria Veraci Queiroz ${ }^{1}$ \\ Maria Salete Jorge ${ }^{2}$
}

QUEIROZ, M. V.; JORGE, M. S. Health education strategies and the quality of care and teaching in pediatrics: interaction, connection and trust in professional discourse. Interface - Comunic., Saúde, Educ., v.10, n.19, p.117-30, jan/jun 2006.

An analytic and interpretative study whose objective was to understand the meaning of educational practice in forming a connection between users, the pediatric team and healthcare services. It was based on Cultural Anthropology assumptions and relied on semi-structured interviews with eight professionals from the field under study. The expressions of the professionals showed the points of convergence, representing the social imagery that applies to this professional activity, expressed in the dialogue themes with respect to the language and experiences as a way of providing care and teaching, and connection and confidence as constructs of the process of providing care and teaching. The results highlighted that Health Education permeates aspects of communication and of interpersonal relations, such as respect for the culture of the families and, in this way, fosters the approximation of the professional and the family and the establishment of a connection and of trust, making it possible to improve aspects of the child's health and qualify of life, justifying an incentive to these types of attitudes and the creation of arenas for discussing and learning this process.

KEY WORDS: pediatrics. health education. health promotion. family. culture.

Trata-se de estudo analítico-interpretativo, cujo objetivo foi compreender o significado da prática educativa na formação do vínculo entre os usuários, a equipe pediátrica e os serviços de saúde. Fundamenta-se em pressupostos da Antropologia Cultural, utilizando a entrevista semi-estruturada com oito profissionais da área. As expressões dos profissionais mostram os pontos de convergência, representando o imaginário social sobre esta atividade profissional expressa nas temáticas diálogo com respeito à linguagem e às experiências como forma de cuidar e ensinar e vínculo e confiança como construtos do processo de cuidar e ensinar. Os resultados destacaram que a Educação em Saúde permeia aspectos da comunicação e da relação interpessoal, como respeito à cultura das famílias e, assim, propicia a aproximação do profissional com a família e a formação de vínculo e confiança, permitindo melhorar aspectos da saúde e da qualidade de vida da criança, justificando o incentivo a tais atitudes e à criação de espaços para a discussão e aprendizagem desse processo.

PALAVRAS-CHAVE: pediatria. educação em saúde. promoção da saúde. família. cultura.

\footnotetext{
${ }^{1}$ Enfermeira, Hospital Geral de Fortaleza; docente, Universidade Estadual do Ceará (UECE). <veraciop@hotmail.com>

${ }^{2}$ Coordenadora, Mestrado Acadêmico em Saúde Pública, Universidade Estadual do Ceará. <masabejo@hotmail.com>
} 


\section{Introdução}

Na saúde em geral e, mais especificamente, na saúde da criança, são muitos os obstáculos a serem enfrentados para que ações sejam implementadas com vistas a um novo paradigma que não aquele que prioriza somente a doença, introduzindo conceitos e ações facilitadores de promoção da saúde.

$\mathrm{Na}$ atenção à saúde da criança, há estreita relação entre a Educação em Saúde e a promoção da saúde, visto que as ações implementadas em todos os níveis de atenção, além de tratar e/ ou prevenir doenças, destinam-se, também, a promover o crescimento e desenvolvimento infantil, numa perspectiva de qualidade de vida. As ações de promoção da saúde devem ser acionadas por meio de estratégias que envolvam a coletividade em geral e a família, esta como responsável pela criança e como detentora de um saber que não poderá ser descartado, mas aperfeiçoado e/ ou adaptado ao saber científico dos profissionais.

Com base na experiência de investigação sobre o cuidado da criança, percebemos que, em todos os campos de atuação da pediatria, a Educação em Saúde surge como prática capaz de favorecer a cura e a recuperação, além de promover a saúde, como também dar suporte ao profissional para avaliar as condições da mãe, ou outro qualquer responsável, para assumir, com suficiência, o cuidado da criança. Por conseguinte, todas as oportunidades devem ser aproveitadas para conversar e trocar experiências, percebendo a sua condição de cuidar da criança e demonstrando uma atitude de compreensão e aproximação com a realidade das famílias, ou seja, estabelecendo uma relação intersubjetiva com essas pessoas que buscam os serviços à procura de saúde dos filhos, um objetivo nem sempre alcançado.

Promover a saúde diz respeito a ações que envolvem as coletividades como um todo, não especificando grupos sob risco ou com determinada doença. Numa compreensão estratégica da promoção da saúde, provocam-se mudanças de comportamento organizacional capazes de beneficiar a saúde de camadas mais amplas da população. É oferecida aos indivíduos, grupos e às coletividades uma possibilidade de se conduzirem num comportamento positivo para a saúde, permitindo que desenvolvam maior controle sobre os fatores que a determinam, favorecendo um estilo de vida mais saudável (Candeias, 1997). Desse modo, os usuários e as coletividades devem ser participantes, com liberdade e direito de tomar decisões conscientes sobre sua saúde. Este é um aspecto que requer, dos profissionais, a aquisição de saberes relativos à dinâmica do "ensinar" cuidados à saúde, de modo crítico, reflexivo e transformador. Essa aquisição envolve práticas e conhecimentos conjugados no estabelecimento de uma nova ação em saúde, permeada de utopias e das mudanças possíveis nas realidades.

Nesse sentido, Freire (2001) enfatiza que a utopia exige conhecimento crítico, presença no mundo para denunciar e intervir na realidade desumanizante. Assumir uma presença capaz de observar, comparar, avaliar, decidir e intervir, adotando tão criticamente quanto possível a competência política capaz de transformar. Além de todo esse fecundo ensinamento, Freire nos leva a pensar que, se não é possível realizar certo sonho ou projeto de mundo, devemos usar possibilidades não apenas para falar da desejada utopia, mas para participar de práticas com ela coerentes, como seres 
transformadores. Considerando, ainda, que as pessoas, quando sujeitos de seu aprendizado, identificam seus problemas e tornam-se capazes de intervir, buscando as possíveis soluções, uma adequada prática de Educação em Saúde corrobora o sentido de ampliação da autonomia no cuidado e na promoção da saúde.

Entendemos que educar deve ser um processo de desenvolvimento e capacitação para um interagir consigo mesmo e com o mundo. E, neste sentido, encontramos em Freire $(1998 ; 2001)$ fundamentação para a concepção de Educação em Saúde na perspectiva antropológica, pois ressalta que todo ato educativo deve tornar o homem capaz de refletir sobre sua realidade e intervir ao criar um mundo próprio. Esta criação passa a ser entendida como cultura, não no sentido estático, mas como um ato de (re) criação, tendo em vista a transformação e/ ou adaptação. Assim, as pessoas refletem, recriam e assumem atitudes conducentes à saúde.

Atualmente, com a noção ampliada de saúde, observamos diversos modelos ou paradigmas de educação em saúde. Porém, muitas práticas ainda preservam o modelo reducionista - numa visão biologicista -, o que requer questionamentos e alcance de perspectivas mais integradas e participativas. Uma educação em saúde ampliada pauta-se em ações para além do tratamento clínico e curativo, assim como propostas pedagógicas libertadoras, comprometidas com o desenvolvimento da solidariedade e da cidadania e, conseqüentemente, melhoria da qualidade de vida e da promoção do homem (Shall \& Struchiner, 1999).

Com base nessas perspectivas, afirmamos ser esta a concepção de educação em saúde que deve ser desenvolvida no campo da saúde e, especialmente, na pediatria, pois traz possibilidades de superação das estruturas hoje dominantes, de fragmentação e distanciamento, para integrar idéias e ações com objetivo de melhorar a saúde e a qualidade de vida da criança, proposta principal da atenção integral à saúde da infância. É preciso entender ainda que, no cuidado à saúde da criança, as ações devem ser compartilhadas entre o profissional e a mãe ou responsáveis. O conhecimento profissional poderá ser assimilado pelas famílias, se colocado de maneira compreensiva e numa linguagem coerente com cada cultura. Há de se entender, no entanto, que as famílias preservam, de certa forma, seu modo de cuidar conforme aprendido em seu meio cultural (Queiroz, 1998) e isto é legítimo.

É necessário conhecer significados, expressões e estruturas que mediatizam a vida e a saúde das pessoas de quem cuidamos. Este conhecimento terá impacto sobre a Educação em Saúde e consubstanciará as práticas de cuidado com a criança. Indubitavelmente, as ações aprendidas para o cuidado são efetivadas por meio da confiança e do vínculo estabelecido entre usuários e profissionais. Estes pressupostos são considerados indispensáveis no desenvolvimento da prática educativa com participação, atendendo alguns princípios educativos, ou seja, que as pessoas, no caso, as crianças e as famílias, assumam seu cuidado, tornando-se capazes de trocar idéias e opiniões sobre suas práticas, como meio de validar, adaptar ou modificar formas aceitáveis e benéficas de cuidados à saúde.

Vários motivos nos impulsionaram à elaboração desta pesquisa, tais como: vivenciar na assistência situações de distanciamento na relação da equipe de 
saúde com as mães/famílias e as dificuldades destas em compreender a linguagem do profissional durante a prática educativa. Esse distanciamento acontece por diversos motivos, incluindo as divergências culturais, que dificultam às famílias a apreensão do conhecimento e, conseqüentemente, o aprimoramento das práticas de cuidado com a saúde dos filhos valendo-se dos ensinamentos profissionais.

Com base no contexto abordado, consideramos relevante conhecer o pensamento dos profissionais da área pediátrica, relativamente à Educação em Saúde, destacando o aspecto da relação/comunicação e da formação de vínculos entre profissionais e usuários. Pretendemos contribuir com a compreensão dos profissionais sobre o significado e as dimensões estratégicas da prática educativa no cuidado infantil, para que possam valorizar as propostas da Educação em Saúde, pois são idéias compartilhadas com os sujeitos da pesquisa e que podem ser dimensionadas no campo das práticas, de modo a qualificar as ações educativas na área infantil.

A pesquisa baseou-se em reflexões que conduziram aos questionamentos articulados aos seguintes objetivos: compreender o significado da prática educativa na formação do vínculo entre os usuários, a equipe pediátrica e os serviços de saúde.

\section{Delineamento metodológico}

O estudo constitui uma abordagem interpretativo-analítica sobre o pensamento e as atitudes dos profissionais em relação à Educação em Saúde no cuidado infantil, configurando uma investigação qualitativa segundo os pressupostos da etnografia, de Geertz $(2001 ; 2000 ; 1989)$ e do Discurso do Sujeito Coletivo (DSC), de Lefèvre et al. (2000).

A etnografia é um método de pesquisa que faz a descrição de determinada cultura em um contexto social, com o objetivo de compreender o tema estudado na perspectiva dos participantes (Hammersley \& Atkinson, 1994). Segundo Geertz (1989, p.27), a etnografia trata de "descrever a cultura de forma inteligível, o universo do discurso humano, visto em um contexto social, articulando-o a outras categorias próprias da ação humana". Desse modo, deve-se atentar para o comportamento, pois é por meio dele, ou mais precisamente da ação social, que as formas culturais encontram articulação. 0 autor reforça que todo agrupamento de pessoas cria uma cultura que orienta a visão de mundo dos seus membros e a forma pela qual eles estruturam suas experiências.

Nesta pesquisa, utilizamos a abordagem etnográfica e o DSC. Este, como um modo de organização e análise dos dados, intermediou a apreensão das expressões dos sujeitos envolvidos, por meio dos discursos verbais emitidos. Para a formação do DSC, são utilizadas figuras metodológicas, resultantes da organização dos discursos, como condições necessárias para a análise e a interpretação dos achados. Os sujeitos pesquisados detêm o conhecimento e o conjunto dos discursos correspondentes a uma das descrições possíveis do imaginário social aplicável ao tema que se está pesquisando (Lefèvre et al., 2000).

Seguindo a orientação dos autores mencionados, destacamos na pesquisa a figura da idéia central, entendida como a(as) afirmação(ões) que permite(m) 
traduzir o essencial do conteúdo discursivo apresentado pelos sujeitos em seus depoimentos. Com a idéia central, elaboramos o discurso do sujeito coletivo, que é o discurso-síntese representado coletivamente e que revela a diversidade de sentidos individuais manifestados por todos.

O campo da pesquisa foi um hospital público do Sistema Único de Saúde, na cidade de Fortaleza - Ceará - Brasil, realizada no Ambulatório de Pediatria e no Núcleo de Aleitamento Materno (NAM) dessa unidade de saúde. A escolha dos informantes-chave foi feita de modo intencional, obedecendo a critérios que atendessem a especificidade da temática. Foram escolhidas cinco médicas e três enfermeiras, que se dispuseram a contribuir e constituíam o perfil de sujeitos envolvidos no cuidado e nas práticas de educação em saúde nesse ambiente de cuidado infantil. Procuramos respeitar os aspectos éticos relacionados à instituição e aos sujeitos da pesquisa. O projeto foi aprovado pela Comissão de Ética na Pesquisa em Saúde da instituição; os informantes ficaram cientes do termo de compromisso de ambas as partes (pesquisadores e pesquisandos) e assinaram o termo de consentimento informado. A pesquisa cumpriu as determinações da Resolução no 196/96, que regulamenta as pesquisas envolvendo seres humanos (Brasil, 1996).

A coleta de dados se deu pela observação livre e pela técnica de entrevista gravada. As observações permitiram conhecer as atividades no campo da Educação em Saúde e o modo como os profissionais envolvem a família nesse processo. As entrevistas foram norteadas pelos seguintes questionamentos: de que modo você integra o saber das famílias de crianças que procuram os serviços de saúde com o saber oriundo da sua formação profissional? Quais idéias são consideradas na sua prática para a formação do vínculo entre os usuários e a equipe pediátrica/serviços de saúde na relação de cuidar e educar em saúde?

A análise das informações iniciou-se com a leitura atenta das entrevistas, seguida da codificação dos conteúdos e organização das unidades de sentido que se relacionavam aos objetivos da pesquisa. Seguindo a orientação metodológica do referencial sobre o DSC, estabelecemos as temáticas ilustrativas das idéias centrais. As referidas temáticas foram: o diálogo com respeito à linguagem e às experiências como forma de cuidar e ensinar e o vínculo e a confiança como construtos no processo de cuidar e ensinar.

\section{(Re)construção dos discursos dos profissionais e compreensão da realidade}

Além de cumprir um processo de pesquisa e uma dinâmica investigativa coerentes com a teoria e os passos metodológicos escolhidos, foram reunidas histórias e vivências da prática de ensinar e aprender a cuidar da criança, representadas nas temáticas ilustrativas, que servem à recomposição crítica, reflexiva e transformadora do cotidiano em pediatria e puericultura como práticas essencialmente educativas.

\section{Diálogo no contexto da linguagem e das experiências como forma de cuidar e ensinar}

Nesta categoria de análise, os discursos dos sujeitos da pesquisa permitiram 
perceber os elementos que constituem a prática integrada do cuidar e do ensinar, pois, falar de um implicava incluir o outro com suas características próprias. Permeando essa díade, tivemos a comunicação e suas nuanças, tema que apareceu no contexto da linguagem, das experiências e no resgate ao conhecimento do outro, em interface com a cultura. Estas idéias estão apresentadas na idéia central da temática, formada do recorte das entrevistas.

Idéia Central: Para fazer educação em saúde, é preciso manter uma comunicação adequada com a mãe (ou responsável), conhecer e respeitar a linguagem, as experiências pessoais e sua cultura, acompanhando a aprendizagem e percebendo os comportamentos adotados no cuidado com a criança; é, também, necessário capacitar os profissionais.

DSC: A população [que assistimos] é humilde e tem baixa escolaridade; é preciso o diálogo numa linguagem não-científica, conhecer a realidade da família, orientar de forma que entenda e devolva o que aprendeu, de acordo com sua cultura, respeitando cada pessoa humana em sua sensibilidade e suas crenças, valorizando o que já sabem, sua experiência pessoal, sem gerar conflitos, não impondo, deixando as mães à vontade, inclusive, para que não criem resistências. O respeito à cultura é difícil, pois há muitas idéias arraigadas. O profissional deve acompanhar o que foi ensinado, vendo se ocorreu aprendizagem pela devolução e pelo comportamento das mães, deve informar sobre riscos e fazê-las pensar. A aprendizagem ocorre pela troca de experiências das mães entre si e com a equipe. A equipe, demonstrando como se faz, e a mãe, devolvendo o que foi ensinado. Quando a mãe devolve, significa que teve assimilação. Devemos questionar sobre suas experiências, pois ela aprende a cuidar com o tempo e, então, segue as recomendações. Muitas têm dificuldades, mas retornam ao NAM amamentando. Nós [enfermeiras] somos mais acessíveis, mas os médicos têm mais dificuldades de falar no nível de compreensão da mãe. É preciso capacitar os profissionais.

É possível apreender, a partir do DSC, que os entrevistados dão relevância ao conhecimento da realidade que envolve os sujeitos, alvo da aprendizagem, bem como a adequação da linguagem a ser utilizada na comunicação entre profissionais e usuários. Utilizando nossas observações empíricas, podemos confrontar esses discursos com algumas situações nas quais o profissional tem dificuldade de realizar uma prática educativa coerente com esses discursos. Percebemos posturas incorporadas na relação educador-educando em que este recebe os conhecimentos advindos do saber profissional passivamente, sem questionar, inclusive, as dúvidas. Enquanto o profissional repassa os conhecimentos da sua maneira (científica), sem, às vezes, refletir sobre o que a pessoa entendeu ou apreendeu de tudo que foi repassado. Embora muitos já conheçam que este modelo tradicional não surte o efeito desejado, continuam agindo assim. Para muitos profissionais, educar em saúde é levar à população a compreensão e as soluções consideradas corretas, da forma como sabe o profissional.

Tal atitude permite uma análise crítica sobre as condições em que se dá a Educação em Saúde, assim como os diversos fatores a influenciar os pensamentos e as ações profissionais.

Várias são as considerações feitas para se entender a complexidade desse fenômeno em suas diferentes possibilidades. A linguagem é um dos aspectos 
relevantes na experiência de cuidar e ensinar. Ela faz parte das incertezas e dificuldades na ef etivação da aprendizagem, assunto destacado no DSC, o qual aponta também as experiências das mulheres no processo de cuidar dos filhos.

Para compreender a associação entre a linguagem, as experiências e a construção do conhecimento, podemos recorrer ao pensamento de Berger \& Luckman (2001, p.57), que destacam a linguagem como importante sistema de sinais da sociedade humana para compreender a realidade. Por meio da linguagem, participamos da vida de nossos semelhantes, principalmente na situação face a face. A linguagem comunica significados e "é capaz de se tornar o repositório objetivo de vastas acumulações de significados e experiências". Essa representação da linguagem na vida cotidiana, na transmissão do conhecimento é entendida por muitos autores como cultura.

A cultura, para Geertz (1989, p.21), é um sistema simbólico e pode ser vista nas estruturas expressas e nos princípios ideológicos ou, mais precisamente, no comportamento das coletividades. É por meio do comportamento, das ações sociais, que as formas culturais encontram articulação. Segundo o autor, o ser humano vive em função do sistema simbólico que cria e recria e dá sentido às suas ações. Assim, podemos entender que as concepções de Educação em Saúde, abordadas pelos profissionais, envolvem o sistema cultural a ser valorizado na prática. Há, portanto, necessidade de serem considerados dois sistemas culturais - o profissional e o familiar - os quais mostram condutas universais e condutas diferenciadas mediante o comportamento e a linguagem como modos de expressão cultural, ou seja, a variação simbólica inscrita no modo de viver desses grupos (usuários e profissionais).

Tais discussões nos remetem ao propósito reflexivo da linguagem. Nesse momento do diálogo, é possível elaborar idéias, recuperando, no pensamento, aspectos já conhecidos e estruturando-os em termos de interesses e conveniências. Torna-se relevante incentivar o interesse da mãe (ou responsáveis) em cuidar do filho (da criança), reavendo o conhecimento do que já sabe, despertando-a para novas experiências no aprimoramento do "saber cuidar do filho". No pensamento dos profissionais entrevistados, "ensinar o que já sabem e o que não sabem", corroborando, ainda, as idéias de Berger \& Luckmann (2001, p.66), ao acentuarem que nossos interesses pragmáticos imediatos determinam algumas dessas conveniências, enquanto outras são determinadas por nossa situação geral na sociedade. Considera-se, ainda, que nossas estruturas de conveniência cruzam as estruturas de conveniência dos outros. Por isso, encontramos muitos pontos "interessantes" em comum com outras pessoas de nossa convivência. Assim, podemos pensar no encontro de interesses e conveniências de ambos (famílias e profissionais) em relação à saúde da criança e obter maior êxito nas ações destinadas a esse fim.

Para o profissional ter acesso às experiências e ao conhecimento das mães (ou responsáveis), faz-se necessário escutar, deixar o pensamento fluir espontaneamente, ou seja, voltar a atenção e a reflexão para o que é comunicado. Nesse sentido, sobressai a idéia de ser a linguagem uma das formas mais comuns de tradução do pensamento. E, como explica Geertz (2001, p.30-1), "o pensamento é conduta e deve ser tratado como tal". Para 
o autor, "as conseqüências do pensamento refletem, inevitavelmente, a qualidade do tipo de situação humana em que foram produzidas".

Tal situação, comentada em relação à postura profissional, corresponde à maneira adequada do profissional agir para motivar a mãe a falar, facilitando o entendimento com vistas a aprender o que foi ensinado. Uma posição contrária produz relacionamento hostil, indiferente, e não manifestações adequadas ao ato de ensinar e aprender. Conseqüentemente, não haverá aproximação intersubjetiva nem troca de saberes capaz de favorecer mudanças e/ou adequações na maneira de cuidar da criança.

No ambiente desta pesquisa, houve momentos da prática educativa em grupos, quando se reuniam várias mães no NAM e no Ambulatório de Pediatria e formavam-se grupos de interesses, algumas delas ainda no puerpério imediato, outras vindas de casa com destino a uma consulta para o filho doente. No NAM, os objetivos de repassar conhecimentos sobre cuidados com a criança consistem, principalmente, do desenvolvimento de atitudes para a prática da amamentação. As questões envolvidas no processo educativo são destacadas, principalmente, nos relatos dessas mulheres sobre as dificuldades encontradas no cuidado com o filho e na revelação de sentimentos e preocupações com o estado de saúde da criança. Trata-se de experiências trocadas entre as mães (participantes do grupo), facilitadas pelas profissionais que ali estavam, motivando, explicando e apoiando cada mãe que se manifestava por meio de palavras ou gestos em relação ao cuidado do filho.

No Ambulatório de Pediatria, a prática de Educação em Saúde é direcionada, quase exclusivamente, aos cuidados relativos à medicação prescrita, pois inexiste qualquer ação planejada junto aos usuários do setor. Nesse serviço, percebemos, ainda, a necessidade de integração com os diversos setores de atendimento à criança. Essa falta de integração mostrava-se claramente no movimento das mães, na dificuldade do atendimento e na falta de acolhimento por parte dos profissionais, portanto, o atendimento da criança não era facilitado, o que causava tumulto e insatisfação por parte das mães e/ ou dos pais que acompanhavam seus filhos.

Estas foram situações reais da prática assistencial nas quais as ações educativas se tornam ausentes, embora no discurso dos profissionais elas estejam presentes, configuradas como repasse de informações e orientações para os cuidados com a doença e o tratamento da criança, sem uma conotação mais adequada sobre a essência da Educação em Saúde.

As estratégias de Educação em Saúde com propósitos definidos devem ter espírito lúdico, compromisso social e, assim, permitir o convívio e interações enriquecedoras entre os participantes. Portanto, devem ser planejadas e executadas de acordo com a condição do serviço e as necessidades levantadas com o grupo de usuários, colaborando na busca de experiências de aprendizagem e reflexão acerca das questões de saúde, respeitando os valores e as experiências dos sujeitos envolvidos no processo.

O DSC elaborado pelos profissionais apresenta, sutilmente, essa atitude que ajuda a solidificar o potencial de cada participante, possibilitando uma atividade de assistência em caráter socioeducativo. Suas declarações envolveram, ainda, as estratégias utilizadas com vistas à aprendizagem da mãe (ou dos responsáveis), as quais não estão distantes das idéias defendidas pelos 
educadores em relação ao ensino-aprendizagem, em que se lança mão da linguagem e das experiências do educando, tornando o ato de aprender um momento real da vida de cada um. Nesse sentido, segundo os entrevistados, a comunicação deve ser eficiente "para que as palavras não fiquem no ar", sem relação com interesses concretos. Nesse discurso há reconhecimento de que, para ocorrer aprendizagem, o conteúdo a ser transmitido deve estar conectado com a realidade dos sujeitos a quem se destina. Então, o profissional deve acompanhar o processo de aprendizagem, dar oportunidade de desenvolvimento do conteúdo ensinado, por meio de sua devolução, onde os resultados podem ser demonstrados pelos comportamentos assumidos mediante o que foi ensinado. Sem dúvida, é na convivência e mantendo diálogo com a mãe (ou responsáveis), captando as atitudes demonstradas por gestos e palavras, que se perceberá o entendimento dela (dos responsáveis) em relação ao cuidado com a criança, embora muitas situações sobre esse cuidado só aconteçam no ambiente privado do domicílio. Uma conversa espontânea e confiante trará informações relevantes para o profissional decidir, junto ao responsável pela criança, como fazer melhor pela sua saúde.

Na prática de Educação em Saúde, significa oportunidade de conhecer mais as pessoas, seus contextos e sua linguagem. Certamente, esta ação realizada em um grupo de mães interessadas com a saúde do filho, trará uma participação de modo a obter conhecimentos para desenvolver habilidades e atitudes favoráveis à saúde da criança. Nesse caso, deve-se facilitar a participação das mães e o entendimento sobre a maneira de cuidar coerente com a realidade dos sujeitos. Nesse sentido, é indispensável utilizar uma linguagem simples e compreensiva, denotando o inestimável respeito à cultura, expressa essencialmente por meio da linguagem.

É preciso dar atenção a esse mundo cotidiano das mulheres-mães, representado pela linguagem do cotidiano, rica em significados. As mulheres que trazem os filhos aos serviços de saúde expressam, nos gestos, além do que está nas palavras, sua condição de vida, implicitamente. Além da doença física, um mundo de relações a repercutir no processo saúde-doença. Assim, a comunicação não pode ser linear e atemporal, porquanto deve haver a leitura de suas expressões, considerando-se, ainda, o contexto em que se dão os acontecimentos. Essa dimensão sobre o ser no mundo remete ao entendimento sobre cultura que, na leitura de Geertz (2001; 1989), está na mente e no coração de cada um.

Conforme expressaram os profissionais, o desrespeito aos aspectos culturais da mãe pode trazer resistência e indiferença ao que foi ensinado. Na relação cuidar-educar, se for desconsiderada a cultura dos usuários, é possível não se atingir os objetivos previstos nesta ação, pois haverá conflito de idéias pelas maneiras variadas de pensar a realidade, levando à indiferença ou à resistência aos modos de pensar de outras culturas. Observar e entender a cultura do outro, tanto no cuidado como nas ações educativas, é uma necessidade, porquanto observação e entendimento fazem parte da ação profissional. Assim, não podemos desconsiderar a Educação em Saúde quando cuidamos ou ensinamos a cuidar.

A experiência de cuidar articulada com a Educação em Saúde deve ocorrer com base na interpretação da cultura. O profissional que articula esse 
conhecimento, isto é, que busca informações, observa e procura entender o significado das palavras no contexto cultural, dispõe de instrumentos essenciais capazes de conduzir sua "ação educativa". Conforme expresso nas entrevistas, "de acordo com a cultura", sendo possível não originar conflitos ou imposições, prevenindo resistências. Este aspecto foi ressaltado pelos entrevistados, os quais reforçaram a idéia de valorizar as experiências, respeitar o saber constituído e a cultura. Tal atitude é reconhecida pela Antropologia Cultural como coerente e humanística, pois evita o conflito de idéias e a imposição do profissional.

\section{Vínculo e confiança como construtos no processo de cuidar e ensinar}

Esta categoria, construída com base nos discursos dos profissionais, mostra a idéia de formação de vínculo e confiança intermediada pelo processo comunicativo imbricado nas relações interpessoais entre usuário e profissional da área pediátrica. Demonstra, pois, que cuidar-ensinar requer, antes de tudo, a aproximação entre usuários e profissionais para que ambos se conheçam e desenvolvam entre si confiança e vínculo observáveis durante as interações. $\mathrm{Na}$ elaboração do DSC, estes aspectos são ressaltados como condição essencial de efetivação das ações educativas para o cuidado à saúde.

Idéia central: devemos apoiar a mãe, informando-a e tranqüilizando-a sobre a condição de saúde de seu filho, procurando entendê-la nas suas condições; passar confiança e coragem, formando vínculo, pois muitas gostam do atendimento e o continuam, mesmo com dificuldades financeiras.

DSC: [Na prática de Educação em saúde] é preciso ter uma relação de confiança, conversar com cada mãe, sensibilizá-la e aos familiares, mostrando o ganho de peso, a curva de crescimento, a amamentação, passando confiança e ajudando-a a entender [...] Algumas não compreendem e não falam por vergonha, então, devemos falar e perguntar de outra maneira, sermos acessíveis para que nos entendam. Ao mandarmos voltar com a criança, ela vai se acostumando e aprende a confiar. O retorno dela ajuda a tranqüilizá-la sobre a condição da criança e a não abandonar a amamentação. Só se consegue educar com o tempo. A informação é dada, mas é difícil saber se houve fixação se não tivermos o retorno da mãe. Procuramos convencê-la a retornar com a criança. Muitas gostam do atendimento e continuam, mesmo com dificuldades financeiras, pois, mantêm a confiança no serviço e nos profissionais.

Recuperando o DSC para enfocar os aspectos educativos envolvendo os profissionais da área infantil e as mães (ou responsáveis) que procuram os serviços de saúde, percebemos que os informantes transmitem a idéia de que cuidar e ensinar estão conjugados numa dinâmica elaborada por meio do vínculo e da confiança, atributos às vezes invisíveis ou adormecidos diante de uma prática mecanizada, rotinizada e normatizadora. Na área pediátrica, principalmente, somos invocados a perceber, a ter sensibilidade e a responder aos apelos surgidos nos cuidados com a saúde da criança, a envolver também a família.

Esta sensibilidade se transforma em ação quando somos capazes de escutar, interagir de forma afetiva e pensar nos resultados deste empreendimento 
indispensável à existência humana; agir integrando virtudes de uma ação e de um fazer com predomínio da razão sensível, estabelecendo maneiras de reaver os direitos dos usuários, cultivando uma relação humanizada.

Na prática, podemos entender tais estratégias como simples, pois não requerem o uso de tecnologias avançadas; envolvem o entendimento do ser humano em suas condições de sobrevivência, numa busca por atenção e cuidados que podem ser dispensados de variadas formas. O desvelamento das necessidades da criança em relação à sua saúde e a própria condição de ajudar a mãe (ou responsável) a promover o cuidado podem ocorrer na interação, na conversa e na atenção individualizada, em que as subjetividades se encontram, se descobrem e superam o jogo de normas e relacionamentos indiferentes a permear as instituições de saúde. Nas palavras de Faria (1996), este é um aspecto a ser superado pelos profissionais, pois estão presos a uma rede organizativa cada vez mais burocratizada e, em conseqüência, há menos espaços de comunicação, impedindo aos usuários a codificação e decodificação das mensagens provenientes do sistema de saúde. Mesmo as ações com caráter preventivo, ações educativas no âmbito da assistência, tornam-se um jogo simulado, nem sempre aceitável pelos usuários por serem momentos rápidos e, às vezes, fora dos contextos em que vivem as pessoas.

Em situações da área pediátrica, segundo observamos, nem sempre a mãe (ou responsável) age dentro das concepções profissionais. Às vezes, procura meios de ajudar a criança conforme suas crenças, utilizando estratégias realizáveis dentro da sua possibilidade, utilizando-se da astúcia e do jogo duplo, pois, para o profissional, ela confirma a possibilidade de cumprir receitas, embora em alguns momentos negue o afirmado. Assim, é preciso considerar tais aspectos no sentido de amenizar contradições entre o esperado pelo profissional e o realizado pela mãe (ou responsável). Como sabemos, as concepções profissionais muitas vezes divergem do entendimento das mães (ou responsáveis), pois os saberes e as vivências são constituídos em contextos diferentes.

Nos discursos, ficou evidente que o despertar da mãe para o cuidado da criança não depende somente das informações/ orientações dadas e recebidas; é preciso sentir-se segura, valorizada em sua singularidade. Significa, para o profissional, acompanhar o que foi ensinado e tranqüilizá-la para ter confiança em si e nos profissionais, atitudes que não se concretizarão em um único e rápido contato. O vínculo formado entre usuários e profissionais ocorrerá nos sucessivos contatos, respeitando-se a individualidade de cada mãe ao longo das interações. Dessa maneira, serão estabelecidos a confiança e o vínculo por meio de uma equipe voltada para o "acolhimento" em defesa da saúde infantil.

Ao tratar dessas prerrogativas na saúde, Costa (2001) acentua que a ef etivação do trabalho vivo em ato, na saúde, se exprime como processo de produção de uma relação intermediada pelo encontro entre os usuários e os trabalhadores de saúde, e vice-versa. É neste encontro que são expressos os componentes vitais, que transpõem os saberes tecnológicos estruturados, aí incluídos o acolhimento e o vínculo.

Atualmente, as ações de acolhimento e vínculo passam a ser prerrogativas do SUS na efetivação dos princípios e diretrizes deste sistema, o qual integra, 
também, a humanização da assistência à saúde. Segundo Vasconcelos (1999), a Educação em Saúde é o campo de práticas e de conhecimentos do setor da saúde que tem se ocupado mais diretamente da criação de vínculos entre a ação, o pensar e o fazer cotidiano da população. Essa idéia favorece a efetivação das ações no campo da Educação em Saúde, e contribui para a transformação da prática, ampliando-se a visão para as dimensões além do corpo doente, recuperando os valores pessoais e a singularidade, e fazendo, mesmo a passos lentos, a humanização dos serviços de saúde em favor da vida - proposta claramente justificada nas ações de Educação em Saúde.

A cada relacionamento positivo aumentam as possibilidades da formação de vínculo e confiança dos usuários com os profissionais e com a instituição, resultando maior eficácia das ações consideradas assistenciais e educativas. A experiência do profissional e o interesse de que a mãe (ou responsável) aprenda e cuide bem do seu filho são elementos a subsidiar uma prática coerente, capaz de transformar-se em ação inovadora. Este entendimento parte da concepção de alguns profissionais que expuseram suas idéias a respeito do assunto. Segundo os discursos dos informantes desta pesquisa, quando as mães (ou responsáveis) são orientadas, quando têm mais contatos com os profissionais, dificilmente deixam de retornar ao serviço para acompanhamento da criança. Esse fato é gratificante, pois a cultura predominante é aquela em que as pessoas procuram os serviços somente quando as crianças estão doentes, desvalorizando o acompanhamento da criança no seu crescimento e desenvolvimento, independentemente de estar doente, ou seja, o serviço de puericultura.

O vínculo e a confiança formados nos contatos dos profissionais com as mães e, principalmente, quando são freqüentes e harmonizantes, vêm garantir a adesão destas aos ensinamentos e às experiências positivas no cuidado da criança. Essa atitude deve ser um estímulo a todos os que cuidam, que reconhecem o direito dos usuários de saúde, não apenas aos cuidados com a doença quando já instalada, mas no dir eito a opções na promoção da saúde e, conseqüentemente, na qualidade de vida. Cabe às instituições de saúde se organizarem para efetivar procedimentos técnicos e humanizados, com a garantia de igualdade na atenção, acesso aos serviços de que necessita cada pessoa e qualidade no cuidado ofertado, o que vai resultar em vínculo e confiança dos usuários com os profissionais e a instituição.

\section{Considerações do estudo}

Levando em conta as questões principais do estudo, foi possível apreendermos parte do imaginário dos profissionais em relação às estratégias de Educação em Saúde e os elementos que contribuem para a formação de vínculos dos usuários com os profissionais e as instituições de saúde. Foi evidenciado nos discursos o fato de a Educação em Saúde ser norteadora do cuidado infantil a oferecer e o fato de se constituir em suporte às famílias para o aprimoramento do cuidado com a criança. Todavia, para que esta ação seja otimizada, é necessário enfatizar o processo relacional, o conhecimento e o respeito às condições da mãe (ou responsável) e a sensibilidade da equipe pediátrica para desenvolver tal atitude.

Na prática, a Educação em Saúde predominante ainda é centrada no saber 
dos profissionais. Mesmo tendo sido destacados, nos depoimentos, aspectos diferentes no desenvolvimento desse processo, algumas idéias e posturas profissionais revelaram o não-dito sobre o paradigma dominante que permeia as ações de Educação em Saúde. Este indicativo é o ponto fundamental a ser refletido, pois evidencia distanciamento, contrariando as necessidades dos usuários (criança/família) e as possibilidades de acesso e vínculo aos serviços, de forma que as mães (ou responsáveis) possam participar ativamente dos cuidados com a saúde do filho (da criança).

Diante de tal postura profissional, estamos cientes de que é necessário rever práticas educativas, com possibilidades de diálogo e escuta sensível sobre as manifestações dos sujeitos responsáveis pelos cuidados com a saúde da criança, facilitando a formação de vínculos e de confiança entre os usuários e os serviços de saúde. Tal fato contribuirá na promoção da saúde infantil, pois a família terá maior disposição e crença na resolubilidade dos seus problemas de saúde.

Compreender esse complexo e, principalmente, incorporar atitudes favoráveis ao processo de cuidar e ensinar pressupõem o empreendimento de aprender a aprender, aprender a fazer, aprender a conviver e aprender a ser, conforme recomenda a Unesco às práticas de educação e ensino. Esses são fios que tecem e garantem todo o sistema de sobrevida humana e envolvem sobremodo a ação educativa de um modo geral.

Vale ressaltar que estas idéias são recortes de uma realidade multidimensional, conflituosa e dinâmica, portanto, em decurso de elaboração, mas tais noções trazem em si reflexões que podem contribuir para mudanças e devem ser acrescidas de outras experiências no campo da pesquisa.

\section{Referências}

BERGER, L. P.; LUCKMANN, T. A construção social da realidade. 20.ed. Petrópolis: Vozes, 2001.

BRASIL. Ministério da Saúde. Conselho Nacional de Saúde. Comissão Nacional de Ética em Pesquisa CONEP. Resolução 196/96 sobre pesquisa envolvendo seres humanos. Brasília, 1996.

CANDEIAS, F. M. Conceitos de educação em saúde e promoção da saúde: mudanças individuais e mudanças organizacionais. Rev. Saúde Pública, v.31, p.209-12, 1997.

COSTA, N. S. S. O acesso da usuária aos serviços e ações de saúde na detecção precoce do câncer de mama: uma abordagem em defesa da vida. 2001. Dissertação (Mestrado) - Universidade Estadual de Feira de Santana, Bahia.

FARIA, E. M. Comunicação na saúde: fim da assimetria...? Pelotas: Ed.Universitária/ UFPel; Florianópolis: Programa de Pós-Graduação em Enfermagem/UFSC, 1998.

FREIRE, P. Educação e mudança. 22.ed. Rio de Janeiro: Paz e Terra, 1998.

FREIRE, P. Pedagogia da esperança: um reencontro com a pedagogia do oprimido. 8.ed. Rio de Janeiro: Paz e Terra, 2001.

GEERTZ, C. A interpretação das culturas. Rio de Janeiro: LTC, 1989.

GEERTZ, C. Nova luz sobre a Antropologia. Rio de Janeiro: Jorge Zahar, 2001.

HAMMERSLEY, M.; ATKINSON, P. Etnografía: métodos de investigación. Barcelona: Paidos, 1994.

LEFÈVRE, F.; LEFÈVRE, A. M. C. Os novos instrumentos da pesquisa qualitativa. In: LEFÈVRE, F.; 
LEFÈVRE, A. M. C.; TEIXEIRA, J. J. V. (Orgs.) O discurso do sujeito coletivo: uma nova abordagem metodológica em pesquisa qualitativa. Caxias do Sul: EDUCS, 2000. p.11-35.

QUEIROZ, M. V. O. Só a mãe conhece o filho: um estudo na etnoenfermagem. 1998. Dissertação (Mestrado) - Universidade Federal do Ceará, Fortaleza.

SHALL, V. T.; STRUCHINER, M. Educação em saúde: novas perspectivas. Cad. Saúde Pública, v.15, supl. 2, p.4-6, 1999.

VASCONCELOS, E. M. Educação popular e a atenção à saúde da família. São Paulo: Hucitec, 1999.

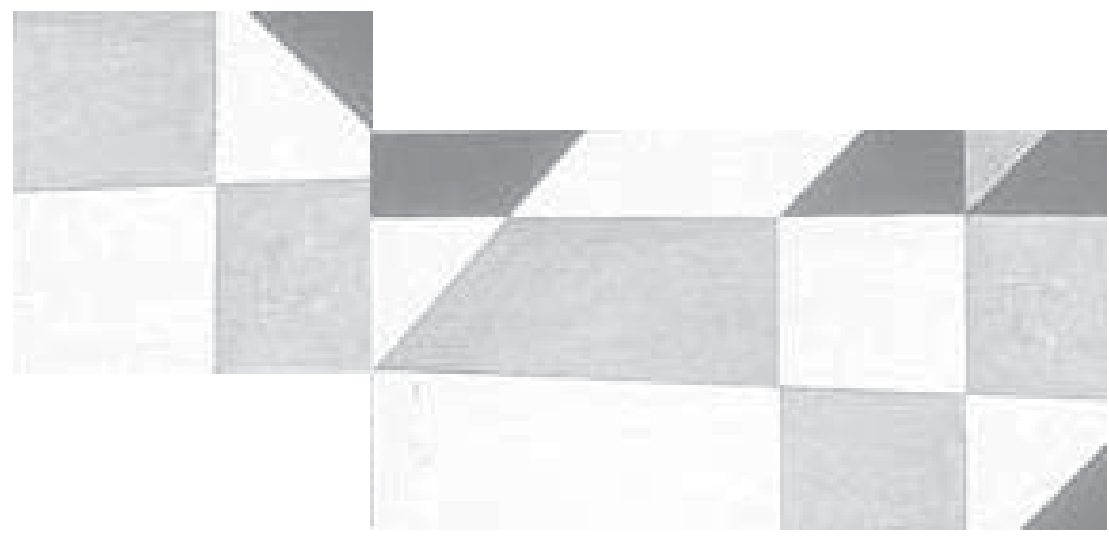

QUEIROZ, M. V.; JORGE, M. S. Estrategias de educación en salud y la calidad del cuidar y enseñar en pediatría: la interacción, el vínculo y la confianza en el discurso de los profesionales. Interface - Comunic., Saúde, Educ., v.10, n.19, p.117-30, jan/jun 2006.

Estudio analítico e interpretativo, cuyo objetivo fue comprender el significado de la práctica educativa en la formación del vínculo entre los usuarios, el equipo pediátrico y los servicios de salud. Está fundamentado en presupuestos de la Antropología Cultural, ha sido utilizada la entrevista semiestructurada con ocho profesionales del área. Las expresiones de los profesionales señalaron los puntos de convergencia, representando el imaginario social sobre esta actividad profesional expresa en las temáticas diálogo con respecto al lenguaje y a las experiencias como forma de cuidar y enseñar, y vínculo y confianza como constructores del proceso de cuidar y enseñar. Los resultados destacaron que en la Educación en Salud intervienen aspectos de la comunicación y de la relación interpersonal como respeto a la cultura de las familias y, así, propicia la aproximación del profesional con la familia y la formación de vínculo y confianza, permitiendo mejorar aspectos de la salud y de la calidad de vida del niño, justificando el incentivo a tales actitudes y a la creación de espacios para la discusión y aprendizaje de ese proceso.

PALABRAS CLAVE: pediatría. educación en salud. promoción de la salud. familia. cultura. 